\title{
Evaluation of the 5-fluorouracil plasma level in patients with colorectal cancer undergoing continuous infusion chemotherapy
}

\author{
YU ABE $^{1,2}$, NAOKI SAKUYAMA ${ }^{1}$, TSUYOSHI SATO ${ }^{1}$, KENJI KISHINE $^{1}$, \\ KIICHI NAGAYASU ${ }^{1}$, AKINORI NAKATANI ${ }^{1}$, MASAYUKI KITAJIMA ${ }^{1}$, TOMOO WATANABE ${ }^{1}$, \\ KAZUHIKO NISHIMURA $^{1}$, TAKUMI OCHIAI ${ }^{1}$ and ISAO NAGAOKA ${ }^{2}$ \\ ${ }^{1}$ Department of Surgery, Tobu Chiiki Hospital, Tokyo Metropolitan Health and \\ Medical Treatment Corporation, Tokyo 125-8512; ${ }^{2}$ Department of Host Defense and Biochemical Research, \\ Juntendo University Graduate School of Medicine, Tokyo 113-8421, Japan
}

Received November 1, 2018; Accepted June 14, 2019

DOI: $10.3892 /$ mco.2019.1893

\begin{abstract}
Fluorouracil (5-FU) dosing has traditionally been based on the body surface area (BSA) in colorectal cancer treatment. However, there is accumulating evidence that dosing based on BSA may be of limited use. The purpose of the present study was to evaluate the changes in 5-FU plasma levels and tumor response as well as the severity of adverse events in patients with cancer treated with 5-FU combined chemotherapy. The dosing amount of 5-FU was determined based on the BSA. Blood samples were collected, and 5-FU plasma levels in 15 patients with colorectal cancer were measured three times $(0,22$ and $40 \mathrm{~h}$ before and after the start of infusion) during constant-infusion of 5-FU for $46 \mathrm{~h}$ by an immunoassay. 5-FU plasma levels were significantly higher at 22 and $40 \mathrm{~h}$ compared with at $0 \mathrm{~h}(\mathrm{P}<0.001)$, when all 15 patients were analyzed. Notably, the tumor response of the partial response/stable disease group showed significant increases in 5-FU plasma levels at $40 \mathrm{~h}$ compared with at $22 \mathrm{~h}(\mathrm{P}<0.01)$, while the progressive disease group showed no significant increase. In addition, the 5-FU plasma level in the adverse event level of grade $\geq 2$ was higher than that of grade $<2$ at $40 \mathrm{~h}$ after the start of infusion. Collectively, these observations indicated that during continuous infusion of 5-FU, the 5-FU plasma level increased significantly, and the tumor response (such as partial response, stable or progressive disease) may be influenced by the increase of 5-FU plasma level from the start of infusion. Therefore, the 5-FU plasma level may be a predictive factor for maximizing the tumor response and minimizing the risk of severe adverse events.
\end{abstract}

Correspondence to: Professor Isao Nagaoka, Department of Host Defense and Biochemical Research, Juntendo University Graduate School of Medicine, 2-1-1 Hongo, Bunkyo-ku, Tokyo 113-8421, Japan E-mail: nagaokai@juntendo.ac.jp

Key words: 5-fluorouracil, chemotherapy, colorectal cancer, plasma level, tumor response, adverse events

\section{Introduction}

Colorectal cancer is one of the leading causes of cancer mortality worldwide $(1,2)$. Since the introduction of 5-fluorouracil (5-FU) in the 1960s, 5-FU has been widely used in colorectal cancer treatment, as well as for other malignancies, including gastric cancer, breast cancer, and head and neck cancer (3). Subsequently, 5-FU-based combination therapies, such as 5-FU plus folinic acid-oxaliplatin (FOLFOX) and 5-FU plus folinic acid-irinotecan (FOLFIRI) regimens, have been developed (4-6). Previously, the addition of anti-epidermal growth factor receptor monoclonal antibodies, such as cetuximab and panitumumab, and humanized anti-vascular growth factor receptor monoclonal antibodies, such as bevacizumab, have also proven to enhance the anti-tumor effect (7-12). Despite the development of combined therapy, 5-FU has continued to be the main drug for the treatment of colorectal cancer. However, the calculation of the dosing amount of 5-FU is still simply based only on the body surface area (BSA) (13).

Dosing based on BSA is considered convenient and easy to use, yet previous studies have indicated that many patients treated with 5-FU are not given the appropriate dose to achieve optimal plasma concentration $(13,14)$. According to a previous study, only $20-30 \%$ of patients are treated with the appropriate therapeutic range, while $40-60 \%$ are under dosed and 10-20\% are overdosed (15). Previous results have suggested the existence of interpatient and intrapatient pharmacokinetic $(\mathrm{PK})$ variation in 5-FU clearance $(13,16-19)$. Collectively, these previous results indicated that dosing based on BSA is of limited use $(13,19,20)$. Therefore, the concept of direct monitoring of 5-FU plasma concentrations with appropriate dose adjustments has been introduced. A number of previous studies, including a large multicenter randomized trial, have shown that PK-guided dose adjustment of 5-FU in metastatic colorectal cancer has resulted in an improvement in therapeutic outcomes and reduced the severity of adverse events $(14,20)$. The aim of the present study was to determine an optimal method of determining the 5-FU dosage for patients with colorectal cancer undergoing chemotherapy. In the present prospective study, the transition of 5-FU plasma levels in patients with colorectal cancer during treatment with 
5-FU combined chemotherapy was monitored. Furthermore, the association between the tumor response and adverse events [classified by the Common Terminology Criteria for Adverse Events (CTCAE) version 5.0] (21) based on the 5-FU plasma levels was evaluated.

\section{Patients and methods}

Patient treatment and eligibility. The present prospective study was performed using 15 patients with colorectal cancer treated with 5-FU combined chemotherapy at The Tobu Chiiki Hospital. All patients were subjected to standardized clinical practice, according to the Japanese Society for Cancer of the Colon and Rectum Guidelines 2016 for the Treatment of Colorectal Cancer (22). 5-FU combined chemotherapy included modified FOLFOX6 (mFOLFOX6) ( $\mathrm{n}=6)$ : Oxaliplatin $85 \mathrm{mg} / \mathrm{m}^{2}$ for $2 \mathrm{~h}$, leucovorin (folinic acid) $200 \mathrm{mg} / \mathrm{m}^{2}$ for $2 \mathrm{~h}, 5-\mathrm{FU} 400 \mathrm{mg} / \mathrm{m}^{2}$ bolus and 5 -FU $2,400 \mathrm{mg} / \mathrm{m}^{2}$ continuous intravenous infusion for $46 \mathrm{~h}$; or FOLFIRI ( $\mathrm{n}=9$ ): Irinotecan $150 \mathrm{mg} / \mathrm{m}^{2}$ for $2 \mathrm{~h}$, leucovorin $150 \mathrm{mg} / \mathrm{m}^{2}$ for $2 \mathrm{~h}, 5-\mathrm{FU} 400 \mathrm{mg} / \mathrm{m}^{2}$ bolus and $5-\mathrm{FU} 2,400 \mathrm{mg} / \mathrm{m}^{2}$ continuous intravenous infusion for $46 \mathrm{~h}$. All patients received the dose of 5-FU based on their BSA (5-FU $400 \mathrm{mg} / \mathrm{m}^{2}$ bolus and 5 -FU $2,400 \mathrm{mg} / \mathrm{m}^{2}$ continuous intravenous infusion for both mFOLFOX6 and FOLFIRI regimens). The Eastern Cooperative Oncology Group Performance Status (ECOG-PS) classification (23) was used to evaluate the performance status (PS) of each patient. Patients were required to have a PS $\leq 2$. The criteria for the classification of PS were as follows: i) PS 0, fully active, able to carry on pre-disease performances without restriction; ii) PS 1, restricted in physically strenuous activity but ambulatory and is able to carry out work of a light or sedentary nature; and iii) PS 2, ambulatory and capable of all selfcare but unable to carry out any work activities; up and about more than 50\% of waking hours. All the patients included in the present study were treated under the guidance of professional medical staff members. Patients were required for 4 days in admission for treatment and were readmitted every 2 weeks for 3 months (a total of six admissions). The present study was approved by the Ethics Committee of Tobu Chiiki Hospital (approved December 21, 2015; IRB nos. 15 and 4), and performed between January 1, 2017 and March 31, 2017. The present study was conducted in accordance with the principles of the amended 'Declaration of Helsinki and Ethical Guidelines for Epidemiological Research' (established by the Japanese Government in 2008) (24). Written informed consent was obtained from all patients before they were enrolled in the present study. Patients with PS $>2$ or requiring radiation or dialysis, or those unable to provide informed consent were excluded.

Measurement of 5-FU plasma levels. Venous blood samples $(10 \mathrm{ml})$ were collected three times during admission (prior to the start of infusion, and 22 and $40 \mathrm{~h}$ after the start of continuous 5-FU infusion). 5-FU plasma levels were measured using the My-5FU ${ }^{\circledR}$ assay, a competitive homogeneous nanoparticle agglutination immunoassay (FALCO Biosystems Ltd.). This assay is used for patients receiving 5-FU by continuous infusion to facilitate PK dose adjustment at the next cycle and drug monitoring to achieve an optimal plasma level of the drug. The assay uses two reagents and when they are mixed, the nanoparticles aggregate together. Therefore, the amount of aggregation of nanoparticles determines the 5-FU concentration in plasma samples. 5-FU plasma levels at 0 (prior to the start of infusion), 22 and $40 \mathrm{~h}$ after the start of continuous 5 -FU infusion in each patient were calculated as median values of six admissions and statistically analyzed.

Analysis of tumor response and adverse events. Tumor response to treatment was classified according to Response Evaluation Criteria in Solid Tumors Group (RECIST 1.1) criteria (25) and was evaluated after the 3 month monitoring period. A complete response required the disappearance of every lesion. A partial response required a $\geq 30 \%$ reduction in the cross-sectional area of all lesions. Stable disease required a lesion size decrease $<30 \%$. Progressive disease categorization encompassed any situation in which any one lesion increased in cross-sectional size by $>25 \%$ or a new lesion appeared.

Adverse events during chemotherapy were evaluated just after the infusion of 5-FU (for $46 \mathrm{~h}$ ) on the 4th day of admission, according to the Common Terminology Criteria for Adverse Events (CTCAE) v5.0 (21), based on physical examination and laboratory tests. The severity of adverse events was graded between 1 and 5. Grade 1 consists of the following criteria: i) Mild; ii) asymptomatic or mild symptoms; iii) clinical or diagnostic observations only; and iv) intervention not indicated. Grade 5 is associated with death. Adverse events were assessed on the last day before discharge for each patient.

Statistical analysis. The plasma levels of 5-FU are presented as box-and-whisker plots (containing the minimum, first quartile, median, third quartile and maximum values), unless otherwise stated. The 5-FU plasma levels were measured three times ( $0 \mathrm{~h}$ prior to the start of infusion, 22 and $40 \mathrm{~h}$ after the start of continuous 5-FU infusion) in each patient, calculated as median values of six admissions, and statistically analyzed. Statistical significance was determined by one-way ANOVA with Bonferroni's post hoc test using GraphPad Prism 7 (GraphPad Software, Inc.). Statistical significance for the different tumor responses (complete response, partial response, stable disease and progressive disease) as well as the response rate and disease control rate between mFOLFOX6 and FOLFIRI was determined by a bivariate analysis using JMP 13 software (SAS Institute, Inc.). $\mathrm{P}<0.05$ was considered to indicate a statistically significant difference.

\section{Results}

Patients. A total of 15 patients (5 female and 10 male) were enrolled in the present study. The patient characteristics are summarized in Table I. The mean age was $69.0 \pm 7.3$ (mean \pm SD, range of 52-79) years and the mean BSA was $1.57 \pm 0.18 \mathrm{~m}^{2}$. Based on the ECOG-PS classification (23), 1 patient was categorized as PS 0,11 patients were categorized as PS 1 , and 3 patients were categorized as PS 2 . Only 1 patient had a tumor located in the descending colon, 10 patients had a tumor located in the sigmoid colon and 4 patients had a tumor located in the rectum. In total, 4 patients had a pathological diagnosis of well differentiated adenocarcinoma, 10 patients were diagnosed with moderately differentiated adenocarcinoma and 1 patient was diagnosed with papillary adenocarcinoma, according 
Table I. Patient characteristics.

\begin{tabular}{lc}
\hline Characteristics & Value \\
\hline Age (years) & $69.0 \pm 7.3^{\mathrm{a}}$ \\
Male/Female & $10 / 5$ \\
BSA (m²) & $1.57 \pm 0.18^{\mathrm{a}}$ \\
ECOG-PS classification (0/1/2) & $1 / 11 / 3$ \\
Tumor location (descending/sigmoid/rectum) & $1 / 10 / 4$ \\
Pathological diagnosis (well/moderately/papillary) & $4 / 10 / 1$ \\
Primary or recurrent tumor & $9 / 6$ \\
Metastasis (+/-) & $14 / 1$ \\
Location of metastasis & $6 / 1 / 2 / 5$ \\
(liver/lung/peritoneum/multiple) & \\
Operation (+/-) & $11 / 4$
\end{tabular}

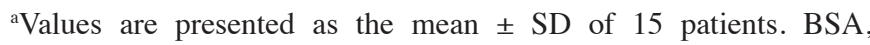
body surface area; ECOG-PS, Eastern Cooperative Oncology Group-Performance Status.

to the Japanese Classification of Colorectal Carcinoma (8th Edition) (26). A total of 9 patients enrolled were treated for a primary tumor, while 6 patients were treated for a recurrent tumor. Among the 9 patients, 8 patients were diagnosed as Stage IV and 1 patient was diagnosed as Stage IIIb, based on the Japanese Classification of Colorectal Carcinoma (8th Edition) (26) (data not shown). The 9 patients were diagnosed with resectable tumors, and thus they were not treated for a neoadjuvant setting. A total of 14 patients had metastasis. The most frequent metastatic site (6 patients) was the liver; other metastasis sites included the lung (1 patient) and peritoneum (2 patients). A total of 5 patients had multiple metastatic sites. A total of 11 out of 15 patients underwent operations.

Changes of the plasma level of 5-FU during infusion. Before the start of infusion, the plasma level of $5-\mathrm{FU}$ was $0 \mathrm{ng} / \mathrm{ml}$ in all patients $(n=15)$. During infusion of $5-\mathrm{FU}$ for $46 \mathrm{~h}$, the level at $22 \mathrm{~h}$ was $460.5 \mathrm{ng} / \mathrm{ml}$ (median value), while the level at $40 \mathrm{~h}$ reached $682.0 \mathrm{ng} / \mathrm{ml}$. The levels at $22 \mathrm{~h}$ and $40 \mathrm{~h}$ were significantly higher than that at $0 \mathrm{~h}(\mathrm{P}<0.001$; Fig. 1). Notably, the level at $40 \mathrm{~h}$ was significantly higher than that at $22 \mathrm{~h}(\mathrm{P}<0.01)$.

Tumor response andregimens. Among the 15 patients, 6 patients underwent chemotherapy of the mFOLFOX6 regimen and 9 patients underwent chemotherapy of the FOLFIRI regimen. The tumor response, according to RECIST 1.1 criteria showed no significant differences between mFOLFOX6 and FOLFIRI in the categories of complete response, partial response, stable disease and progressive disease (Table II). The response rate (proportion of patients who achieved complete or partial response) and the disease control rate (proportion of patients who achieved complete, partial response or stable disease) also showed no significant differences between mFOLFOX6 and FOLFIRI.

Changes of the plasma level of 5-FU in different tumor response groups. The plasma levels of 5-FU in the patients with different tumor responses were examined. In the partial response/stable

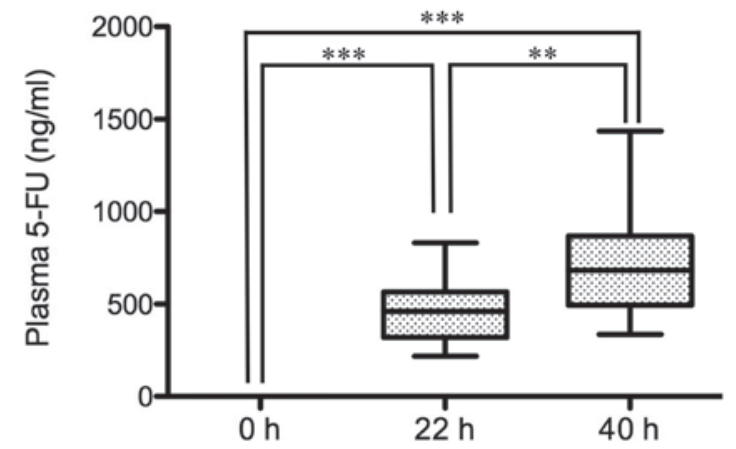

Figure 1. Plasma levels of 5-FU after the start of continuous infusion. Blood samples were collected prior to the start of infusion $(0 \mathrm{~h}), 22$ and $40 \mathrm{~h}$ after the start of continuous 5-FU infusion, and 5-FU plasma levels were measured. The plasma levels of 5-FU of 15 patients enrolled are presented as box-and-whisker plots. Values are compared among 0,22 and 40 h. ${ }^{* *} \mathrm{P}<0.01$, ${ }^{* * * *} \mathrm{P}<0.001 .5$-FU, 5-fluorouracil.

disease group, the 5-FU plasma level at $22 \mathrm{~h}$ after the start of infusion was $460.5 \mathrm{ng} / \mathrm{ml}$ (median value), while the level at $40 \mathrm{~h}$ reached $690.9 \mathrm{ng} / \mathrm{ml}$ (Fig. 2A). The levels at 22 and $40 \mathrm{~h}$ were significantly higher than at $0 \mathrm{~h}(\mathrm{P}<0.001)$. Notably, the level at $40 \mathrm{~h}$ was significantly higher than at $22 \mathrm{~h}(\mathrm{P}<0.01)$. In the progressive disease group, the 5-FU plasma level at $22 \mathrm{~h}$ after the start of infusion was $435.1 \mathrm{ng} / \mathrm{ml}$, while the level at $40 \mathrm{~h}$ reached $525.9 \mathrm{ng} / \mathrm{ml}$ (Fig. 2B). The levels at $22 \mathrm{~h}$ and $40 \mathrm{~h}$ were significantly higher than at $0 \mathrm{~h}(\mathrm{P}<0.05)$. However, the level at $40 \mathrm{~h}$ was not significantly higher than at $22 \mathrm{~h}$.

Furthermore, the mean 5-FU plasma level at $40 \mathrm{~h}$ after the start of infusion between the partial response/stable disease group and the progressive disease group was compared (Fig. 2). The 5-FU plasma level of the partial response/stable disease group $(776.2 \pm 286.9 \mathrm{ng} / \mathrm{ml}$; mean $\pm \mathrm{SD})$ was higher than that of the progressive disease group $(681.9 \pm 369.4 \mathrm{ng} / \mathrm{ml}$; data not shown), although there was no significant difference between the two groups, as assessed by one-way ANOVA analysis with Bonferroni's post hoc test.

Adverse events in different tumor response groups. Table III shows the adverse events of grade $\geq 2$ in the different tumor response groups; grade 2, according to CTCAE v5.0, which is defined according to the following criteria: i) Moderate; ii) minimal, local or noninvasive intervention indicated; and iii) limiting age-appropriate instrumental activities of daily living. In the partial response group, numbness was the most common adverse event (75\%). In the stable disease group, numbness and diarrhea were observed (both 50\%). In the progressive disease group, numbness $(80 \%)$, appetite loss $(60 \%)$ and hand foot syndrome $(60 \%)$ were observed. Adverse events were evaluated after the infusion of $5-\mathrm{FU}$ for $46 \mathrm{~h}$ on the 4 th day of admission. Therefore, this suggests that the 5-FU plasma level at $40 \mathrm{~h}$ after the start of infusion may reflect the results of the adverse events.

Plasma levels of 5-FU in the patients with different severities of adverse events. Among the 15 patients, 13 patients were included in the adverse event level of grade $\geq 2$. In the partial response/stable disease group, 8 out of 9 patients were included in the adverse event level of grade $\geq 2$, whereas in the progressive 
Table II. Tumor response and 5-fluorouracil regimens.

\begin{tabular}{lccc}
\hline Tumor response & $\begin{array}{c}\text { mFOLFOX6 } \\
(\mathrm{n}=6)\end{array}$ & $\begin{array}{c}\text { FOLFIRI } \\
(\mathrm{n}=9)\end{array}$ & P-value \\
\hline Complete response & 0 & 0 & N/A \\
Partial response & 2 & 3 & $>0.99$ \\
Stable disease & 1 & 3 & 0.60 \\
Progressive disease & 3 & 3 & 0.52 \\
Response rate & $33 \%$ & $33 \%$ & $>0.99$ \\
Disease control rate & $50 \%$ & $67 \%$ & 0.52 \\
\hline
\end{tabular}

In total, 6 patients were treated with the mFOLFOX6 regimen and 9 patients were treated with the FOLFIRI regimen. The number of patients with different tumor responses (complete response, partial response, stable disease and progressive disease) in each regimen are listed. The response rate is defined as the proportion of patients with complete or partial response among each regimen. The disease control rate is defined as the proportion of patients with complete, partial response or stable disease among each regimen. Statistical significance was determined by a bivariate analysis. There was no significant difference in each tumor response, response rate or disease control rate between the two regimens. mFOLFOX, modified 5-fluorouracil plus folinic acid-oxaliplatin; FOLFIRI, 5-fluorouracil plus folinic acid-irinotecan; N/A, not applicable.
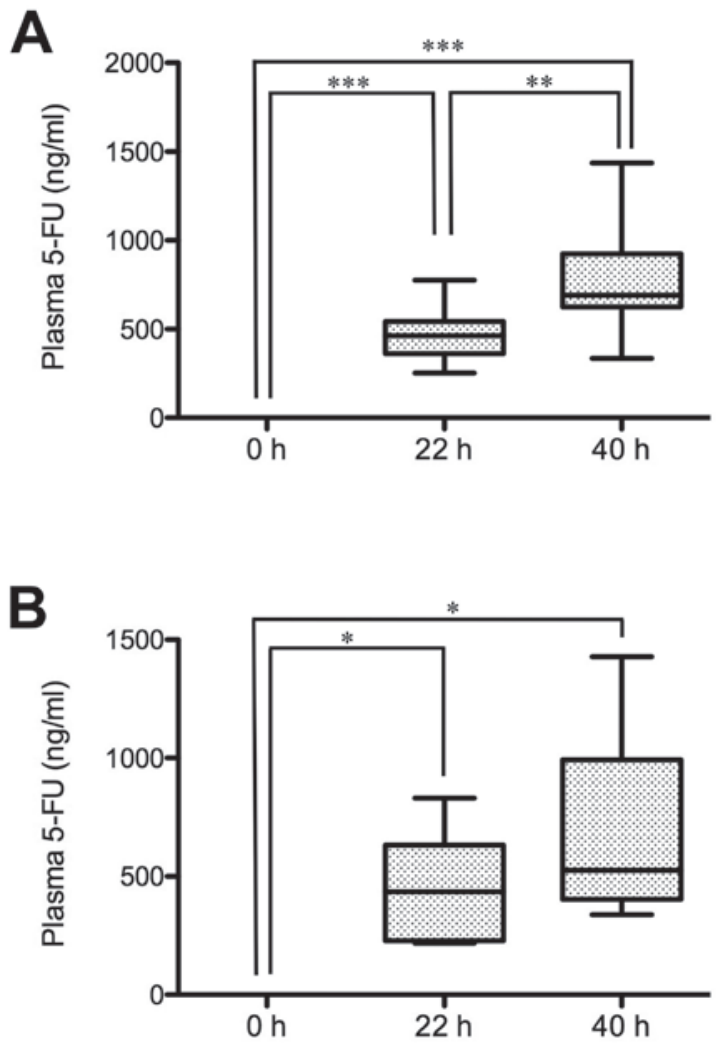

Figure 2. Plasma levels of 5-FU in the patients with different tumor responses after the start of continuous infusion. Blood samples of patients in (A) the partial response/stable disease group and (B) the progressive disease group were collected prior to the start of infusion $(0 \mathrm{~h}), 22$ and $40 \mathrm{~h}$ after the start of continuous 5-FU infusion, and 5-FU plasma levels were measured. The plasma levels of 5-FU of the partial response/stable disease group $(n=9)$ and the progressive disease group $(n=6)$ are presented as box-and-whisker plots. Values are compared among 0,22 and $40 \mathrm{~h} .{ }^{*} \mathrm{P}<0.05,{ }^{* *} \mathrm{P}<0.01,{ }^{* * * *} \mathrm{P}<0.001$. 5-FU, 5-fluorouracil. disease group, 5 out of the 6 patients were included to have an adverse event level of grade $\geq 2$. 5-FU plasma levels at $40 \mathrm{~h}$ after the start of infusion in the adverse event level of grade $\geq 2$ (13 patients in the partial response/stable disease and progressive disease groups) reached $690.9 \mathrm{ng} / \mathrm{ml}$ (median value), while the 5-FU plasma level for the adverse event level of grade $<2$ ( 2 patients in the partial response/stable disease and progressive disease groups) was $591.6 \mathrm{ng} / \mathrm{ml}$ (Fig. 3). Although there was no statistical significance between the groups of grades $\geq 2$ and $<2$, the 5 -FU plasma level was $\sim 100 \mathrm{ng} / \mathrm{ml}$ higher in the group of grades $\geq 2$ than that in the group of grade $<2$.

\section{Discussion}

5-FU dosing has traditionally been based on BSA in colorectal cancer treatment. However, there is accumulating evidence that the dosing based on BSA may be of limited use (13). The purpose of the present study was to evaluate the changes in 5-FU plasma levels and the tumor response as well as the severity of adverse events in patients with cancer treated with 5-FU combined chemotherapy (mFOLFOX6 and FOLFIRI). The dosing amount of 5-FU was determined based on the BSA, and the transition of 5-FU plasma levels in 15 patients with colorectal cancer was monitored three times (0,22 and $40 \mathrm{~h})$ before and after the start of infusion during constant-infusion of 5-FU for $46 \mathrm{~h}$. The present study demonstrated that 5-FU plasma levels were significantly higher at 22 and $40 \mathrm{~h}$ compared with at $0 \mathrm{~h}$, when all 15 patients were analyzed. Notably, the partial response/stable disease group showed significant increases in 5-FU plasma levels at $40 \mathrm{~h}$ compared with at $22 \mathrm{~h}$, although the progressive disease group showed no significant increase. In addition, the 5-FU plasma level in the adverse event level of grade $\geq 2$ was higher than that of grade $<2$ at $40 \mathrm{~h}$ after the start of infusion.

A significant increase in the 5-FU plasma level at $40 \mathrm{~h}$ compared with $22 \mathrm{~h}$ after the start of infusion was observed. In order to explain the wide range of increases in 5-FU plasma levels, a number of previous studies suggested that dihydropyrimidine dehydrogenase (DPD), an initial rate-limiting enzyme related to 5-FU metabolism, plays a role in determining the plasma levels of 5-FU (27-30). Therefore, the significant increase in 5-FU plasma levels after continuous intravenous infusion (particularly between 22 and $40 \mathrm{~h}$ ) observed in the partial response/stable disease group may be due to the decreased 5-FU-metabolizing activity of DPD. However, the non-significant increase of 5-FU plasma level in the progressive disease group (between 22 and $40 \mathrm{~h}$ ) may suggest that the 5-FU-metabolizing activity of DPD is higher than that of the partial response/stable disease group. Furthermore, the present results suggested that the tumor response may be influenced by the increase of 5-FU plasma level (possibly based on the low DPD activity) after the start of continuous infusion, as observed in the higher plasma 5-FU level in the partial response/stable disease group, compared with the progressive disease group, suggesting that a high DPD activity may be associated with a poor prognosis in the tumor response. However, DPD activity was not evaluated in the present study. Therefore, DPD activity should be evaluated in future studies.

In contrast to a previous study (18), in which the 5-FU plasma level reached a plateau at $22 \mathrm{~h}$ after the continuous infusion with an electronical pump, the present study showed that the 5-FU 
Table III. Tumor response and severity of adverse events.

\begin{tabular}{lccc}
\hline Adverse events & Partial response, $\%$ & Stable disease, $\%$ & Progressive disease, $\%$ \\
\hline Hand foot syndrome & 50 & 0 & 60 \\
Fatigue & 0 & 25 & 40 \\
Edema & 0 & 25 & 40 \\
Stomatitis & 50 & 25 & 40 \\
Appetite loss & 25 & 25 & 60 \\
Numbness & 75 & 50 & 80 \\
Neutropenia & 0 & 0 & 20 \\
Nausea/Vomit & 25 & 0 & 0 \\
Facial flushing & 0 & 0 & 20 \\
Diarrhea & 0 & 50 & 20
\end{tabular}

The proportion of adverse events among patients of Grade $\geq 2(n=13)$ treated with modified 5-fluorouracil plus folinic acid-oxaliplatin or 5-fluorouracil plus folinic acid-irinotecan is shown for each tumor response (partial response, $n=4$; stable disease, $n=4$; progressive disease, $n=5$ ). Grade 2 is defined according to the following criteria of the Common Terminology Criteria for Adverse Events v5.0: i) Moderate; ii) minimal, local or noninvasive intervention indicated; and iii) limiting age-appropriate instrumental activities of daily living.

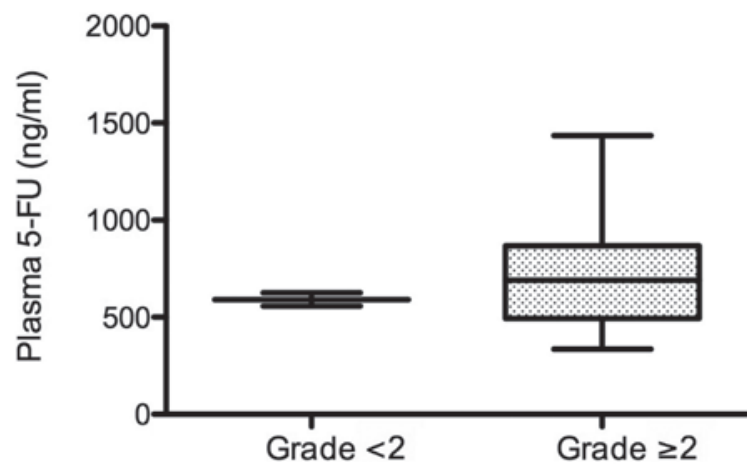

Figure 3. Plasma levels of 5-FU in the patients with different severities of adverse events at $40 \mathrm{~h}$ after the start of infusion. Plasma levels of 5-FU in patients with the severity of adverse events (grade $<2$ and $\geq 2$ ) were compared at $40 \mathrm{~h}$ after the start of infusion. The plasma levels of 5 -FU of grade $<2(n=2)$ and $\geq 2(n=13)$ are expressed in box-and-whisker plots. 5-FU, 5-fluorouracil.

plasma level continued to significantly increase between 22 and $40 \mathrm{~h}$ after infusion. In the previous study (18), 5-FU continuous infusion relied on an elastomeric infusion pump that is suitable for ambulatory patients treated in an out-patient clinic. In the present study, professional staff members constantly monitored the electronical infusion pump to prevent the discontinuity of 5-FU during admission. Therefore, the infusion methods used in the present study may explain a continuous increase of 5-FU plasma levels during $40 \mathrm{~h}$ from the start of admission. Furthermore, the increase in the 5-FU plasma level may also explain the adverse events occurring in the partial response/stable disease group. However, it is not possible to conclude that an elastomeric pump is inferior to an electronical infusion pump. Previous studies have suggested that patients prefer elastomeric balloon infusion pump rather than an electronical infusion pump, as the weight and size of elastomeric infusion pump is low $(31,32)$. However, it has been reported that the accuracy in delivery rate of an elastomeric infusion pump is lower compared with an electronical infusion pump $(33,34)$. Therefore, the accuracy of the delivery rate in an electronical infusion pump may contribute to the significant increase of the plasma level of 5-FU at $40 \mathrm{~h}$ in the present study. Furthermore, it has also been suggested in a previous study utilizing an electronical infusion pump that acute toxicity was correlated with a high 5-FU plasma level (35). Taking these observations into consideration, it was hypothesized that the high plasma level of 5-FU observed in the partial response/stable disease group may reflect the severity in adverse events shown in the present study.

However, the present study has several limitations. The number of patients enrolled in the present study was limited and the tumor response was evaluated for only a short term of 3 months. Therefore, future studies should monitor patients for a longer period to evaluate the prognosis and overall survival. However, despite these limitations, the present study supports the accumulating evidence that measuring 5-FU plasma levels may contribute to the improvement of a positive tumor response as well as to minimize the risk of severe adverse events $(14,20)$. Furthermore, it is difficult to discuss the effect of 5-FU for tumor response and adverse event in the protocol of FOLFOX or FOLFIRI using oxaliplatin or irinotecan, respectively. However, to the best of our knowledge, a standardized method has not yet been developed to evaluate the plasma levels of oxaliplatin or irinotecan. Notably, a previous study has revealed that a higher plasma level of 5-FU undergoing a regimen of continuous 5-FU plus leucovorin with an electronical infusion pump was correlated with more severe toxicities (35). The present study also indicated that a higher 5-FU plasma level results in a positive tumor response. Although the plasma levels of oxaliplatin and irinotecan were not measured in the present study, these previous studies $(15,17,36)$ likely support the hypothesis that a significant increase of 5-FU plasma at $40 \mathrm{~h}$ is associated with the severity of toxicity as well as a positive tumor response.

In conclusion, during continuous infusion of 5-FU, the 5-FU plasma level increased significantly. The tumor response may be influenced by the increase of 5-FU plasma level from the start of infusion. The 5-FU plasma level may be a predictive factor for maximizing the tumor response and minimizing the risk of severe adverse events. 


\section{Acknowledgements}

The authors would like to thank Mr Hiroshi Yamane and Mr Makoto Miyazaki (FALCO Biosystems Ltd.) for measuring the plasma levels of 5-FU in the present study.

\section{Funding}

Funding was provided from Takeda Pharmaceutical Company Ltd. (grant. no. RS2016A001043) and Chugai Pharmaceutical Co., Ltd. (grant. no. AC-1-20170518213426-569401).

\section{Availability of data and materials}

The datasets used and/or analyzed during the present study are available from the corresponding author on reasonable request.

\section{Authors' contributions}

YA and TO designed the research. YA, NS, TS, KK, KNa, AN, MK, TW, KNi and TO performed the clinical study. YA, TO and IN analyzed the data. YA and IN prepared the manuscript. All authors read and approved the final manuscript.

\section{Ethics approval and consent to participate}

The present study was approved by the Ethics Committee of Tobu Chiiki Hospital (approved December 21, 2015; IRB nos. 15 and 4), and performed between January 1, 2017 and March 31, 2017. The present study was conducted in accordance with the principles of the amended 'Declaration of Helsinki and Ethical Guidelines for Epidemiological Research' (established by the Japanese Government in 2008). Written informed consent was obtained from all patients before they were enrolled in the present study.

\section{Patient consent for publication}

All the participants enrolled in the present study provided written informed consent for the publication of any associated data.

\section{Competing interests}

The authors declare that they have no competing interests.

\section{References}

1. Ferlay J, Soerjomataram I, Dikshit R, Eser S, Mathers C, Rebelo M, Parkin DM, Forman D and Bray F: Cancer incidence and mortality worldwide: Sources, methods and major patterns in GLOBOCAN 2012. Int J Cancer 136: E359-E386, 2015.

2. Benson AB III, Venook AP, Cederquist L, Chan E, Chen YJ, Cooper HS, Deming D, Engstrom PF, Enzinger PC, Fichera A, et al: Colon cancer, version 1.2017, NCCN clinical practice guidelines in oncology. J Natl Compr Canc Netw 15: 370-398, 2017.

3. Mayer RJ: Moving beyond fluorouracil for colorectal cancer. N Engl J Med 343: 963-964, 2000.

4. de Gramont A, Figer A, Seymour M, Homerin M, Hmissi A, Cassidy J, Boni C, Cortes-Funes H, Cervantes A, Freyer G, et al: Leucovorin and fluorouracil with or without oxaliplatin as first-line treatment in advanced colorectal cancer. J Clin Oncol 18: 2938-2947, 2000.
5. Saltz LB, Cox JV, Blanke C, Rosen LS, Fehrenbacher L, Moore MJ, Maroun JA, Ackland SP, Locker PK, Pirotta N, et al: Irinotecan plus fluorouracil and leucovorin for metastatic colorectal cancer. Irinotecan Study Group. N Engl J Med 343: 905-914, 2000.

6. Tournigand C, Andre T, Achille E, Lledo G, Flesh M, Mery-Mignard D, Quinaux E, Couteau C, Buyse M, Ganem G, et al: FOLFIRI followed by FOLFOX6 or the reverse sequence in advanced colorectal cancer: A randomized GERCOR study. J Clin Oncol 22: 229-237, 2004

7. Cunningham D, Humblet Y, Siena S, Khayat D, Bleiberg H, Santoro A, Bets D, Mueser M, Harstrick A, Verslype C, et al: Cetuximab monotherapy and cetuximab plus irinotecan in irinotecan-refractory metastatic colorectal cancer. N Engl J Med 351: 337-345, 2004.

8. Hurwitz H,Fehrenbacher L, Novotny W, Cartwright T, Hainsworth J, Heim W, Berlin J, Baron A, Griffing S, Holmgren E, et al: Bevacizumab plus irinotecan, fluorouracil, and leucovorin for metastatic colorectal cancer. N Engl J Med 350: 2335-2342, 2004.

9. Jonker DJ, O'Callaghan CJ, Karapetis CS, Zalcberg JR, Tu D, Au HJ, Berry SR, Krahn M, Price T, Simes RJ, et al: Cetuximab for the treatment of colorectal cancer. N Engl J Med 357: 2040-2048, 2007.

10. Giantonio BJ, Catalano PJ, Meropol NJ, O'Dwyer PJ, Mitchell EP, Alberts SR, Schwartz MA and Benson AB III; Eastern Cooperative Oncology Group Study E3200: Bevacizumab in combination with oxaliplatin, fluorouracil, and leucovorin (FOLFOX4) for previously treated metastatic colorectal cancer: Results from the Eastern Cooperative Oncology Group Study E3200. J Clin Oncol 25: 1539-1544, 2007.

11. Wu M, Rivkin A and Pham T: Panitumumab: Human monoclonal antibody against epidermal growth factor receptors for the treatment of metastatic colorectal cancer. Clin Ther 30: 14-30, 2008.

12. Peeters M, Price TJ, Cervantes A, Sobrero AF, Ducreux M, Hotko Y, Andre T, Chan E, Lordick F, Punt CJ, et al: Randomized phase III study of panitumumab with fluorouracil, leucovorin, and irinotecan (FOLFIRI) compared with FOLFIRI alone as second-line treatment in patients with metastatic colorectal cancer. J Clin Oncol 28: 4706-4713, 2010.

13. Saam J, Critchfield GC, Hamilton SA, Roa BB, Wenstrup RJ and Kaldate RR: Body surface area-based dosing of 5-fluoruracil results in extensive interindividual variability in 5-fluorouracil exposure in colorectal cancer patients on FOLFOX regimens. Clin Colorectal Cancer 10: 203-206, 2011.

14. Patel JN, O'Neil BH, Deal AM, Ibrahim JG, Sherrill GB, Olajide OA, Atluri PM, Inzerillo JJ, Chay CH, McLeod HL and Walko CM: A community-based multicenter trial of pharmacokinetically guided 5-fluorouracil dosing for personalized colorectal cancer therapy. Oncologist 19:959-965, 2014

15. SaifMW, Choma A, Salamone SJ and Chu E: Pharmacokinetically guided dose adjustment of 5-fluorouracil: A rational approach to improving therapeutic outcomes. J Natl Cancer Inst 101: 1543-1552, 2009.

16. Gamelin E, Boisdron-Celle M, Delva R, Regimbeau C, Cailleux PE, Alleaume C, Maillet ML, Goudier MJ, Sire M, Person-Joly MC, et al: Long-term weekly treatment of colorectal metastatic cancer with fluorouracil and leucovorin: Results of a multicentric prospective trial of fluorouracil dosage optimization by pharmacokinetic monitoring in 152 patients. J Clin Oncol 16: 1470-1478, 1998.

17. Ychou M, Duffour J, Kramar A, Debrigode C, Gourgou S, Bressolle $\mathrm{F}$ and Pinguet F: Individual 5-FU dose adaptation in metastatic colorectal cancer: Results of a phase II study using a bimonthly pharmacokinetically intensified LV5FU2 regimen. Cancer Chemother Pharmacol 52: 282-290, 2003.

18. Kaldate RR, Haregewoin A, Grier CE, Hamilton SA and McLeod HL: Modeling the 5-fluorouracil area under the curve versus dose relationship to develop a pharmacokinetic dosing algorithm for colorectal cancer patients receiving FOLFOX6. Oncologist 17: 296-302, 2012.

19. Capitain O, Asevoaia A, Boisdron-Celle M, Poirier AL, Morel A and Gamelin E: Individual fluorouracil dose adjustment in FOLFOX based on pharmacokinetic follow-up compared with conventional body-area-surface dosing: A phase II, proof-of-concept study. Clin Colorectal Cancer 11: 263-267, 2012.

20. Gamelin E, Delva R, Jacob J, Merrouche Y, Raoul JL, Pezet D, Dorval E, Piot G, Morel A and Boisdron-Celle M: Individual fluorouracil dose adjustment based on pharmacokinetic follow-up compared with conventional dosage: Results of a multicenter randomized trial of patients with metastatic colorectal cancer. J Clin Oncol 26: 2099-2105, 2008. 
21. Cho J, Yoon J, Kim Y, Oh D, Kim SJ, Ahn J, Suh GY, Nam SJ and Mitchell SA: Linguistic validation of the US national cancer institute's patient-reported outcomes version of the common terminology criteria for adverse events in Korean. J Glob Oncol 5: 1-10, 2019.

22. Watanabe T, Muro K, Ajioka Y, Hashiguchi Y, Ito Y, Saito Y, Hamaguchi $\mathrm{T}$, Ishida $\mathrm{H}$, Ishiguro $\mathrm{M}$, Ishihara $\mathrm{S}$, et al: Japanese society for cancer of the colon and rectum (JSCCR) guidelines 2016 for the treatment of colorectal cancer. Int J Clin Oncol 23: 1-34, 2018

23. Correa GT, Bandeira GA, Cavalcanti BG, Santos FB, Rodrigues Neto JF, Guimaraes AL, Haikal DS and De Paula AM: Analysis of ECOG performance status in head and neck squamous cell carcinoma patients: Association with sociodemographical and clinical factors, and overall survival. Support Care Cancer 20: 2679-2685, 2012.

24. Skierka AS and Michels KB: Ethical principles and placebo-controlled trials-interpretation and implementation of the Declaration of Helsinki's placebo paragraph in medical research. BMC Med Ethics 19: 24, 2018.

25. Eisenhauer EA, Therasse P, Bogaerts J, Schwartz LH, Sargent D, Ford R, Dancey J, Arbuck S, Gwyther S, Mooney M, et al: New response evaluation criteria in solid tumours: revised RECIST guideline (version 1.1). Eur J Cancer 45: 228-247, 2009.

26. Ishiguro S: Pathological diagnosis of colorectal cancer according to Japanese classification of colorectal carcinoma. Nihon Rinsho 69 (Suppl 3): S325-S329, 2011 (In Japanese).

27. Pinedo HM and Peters GF: Fluorouracil: Biochemistry and pharmacology. J Clin Oncol 6: 1653-1664, 1988.

28. Lu ZH, Zhang R and Diasio RB: Purification and characterization of dihydropyrimidine dehydrogenase from human liver. J Biol Chem 267: 17102-17109, 1992.
29. Diasio RB and Lu Z: Dihydropyrimidine dehydrogenase activity and fluorouracil chemotherapy. J Clin Oncol 12: 2239-2242, 1994.

30. Diasio RB and Johnson MR: Dihydropyrimidine dehydrogenase: Its role in 5-fluorouracil clinical toxicity and tumor resistance. Clin Cancer Res 5: 2672-2673, 1999.

31. Zahnd D, Aebi S, Rusterholz S, Fey MF and Borner MM: A randomized crossover trial assessing patient preference for two different types of portable infusion-pump devices. Ann Oncol 10: 727-729, 1999.

32. Capdevila X, Macaire P, Aknin P, Dadure C, Bernard N and Lopez S: Patient-controlled perineural analgesia after ambulatory orthopedic surgery: A comparison of electronic versus elastomeric pumps. Anesth Analg 96: 414-417, table of contents, 2003.

33. Ganapathy S, Amendola A, Lichfield R, Fowler PJ and Ling E: Elastomeric pumps for ambulatory patient controlled regional analgesia. Can J Anaesth 47: 897-902, 2000.

34. Kaye T: Prolonged infusion times with disposable elastomeric infusion devices. Am J Hosp Pharm 51: 533-534, 1994.

35. Gamelin EC, Danquechin-Dorval EM, Dumesnil YF, Maillart PJ, Goudier MJ, Burtin PC, Delva RG, Lortholary AH, Gesta PH and Larra FG: Relationship between 5-fluorouracil (5-FU) dose intensity and therapeutic response in patients with advanced colorectal cancer receiving infusional therapy containing 5-FU. Cancer 77: 441-451, 1996.

36. Blaschke M, Blumberg J, Wegner U, Nischwitz M, Ramadori G and Cameron S: Measurements of 5-FU plasma concentrations in patients with gastrointestinal cancer: 5-FU levels reflect the 5-FU dose applied. J Cancer Ther 3: 28-36, 2012. 